\title{
PRODUCTION SINGLE-WALLED CARBON NANOTUBES BY CHEMICAL VAPOR DEPOSITION FROM MECHANISM TO PATTERNED GROWTH FOR ELECTRO DEVICES
}

\section{Le Van Thang}

University of Technology or University of Science, VNUHCM

(Manuscript Received on April 5 ${ }^{\text {th }}, 2012$, Manuscript Revised May 15 ${ }^{\text {th }}$, 2013)

ABSTRACT: The ability to controllably obtain ordered carbon nanotube architectures is important to fundamental characterizations and potential applications of electrical devices. Controlled synthesis involving chemical vapor deposition (CVD) has been an effective strategy to order singlewalled nanotubes (SWNTS) on patterned catalyst. In this paper, Single-walled carbon nanotubes are synthesized by chemical vapor deposition of methane at controlled locations on a silicon substrate. This synthetic approach has allowed individual SWNT wires to be grown from controlled surface sites by catalyst patterning and has led to interconnecting SWNT electrical devices. The combined synthesis and microfabrication technique presented here allows a large number of ohmically contacted nanotube devices with controllable length to be placed on a single substrate.

Keywords:Single-walled carbon nanotubes, electrical device, patterned catalyst, interconnecting

\section{INTRODUCTION}

Carbon nanotubes (CNTs) were first discovered by scientists at NEC in 1991 [1]. They exhibit exceptional chemical and physical properties that have opened a large number of potential applications: transistor, nanotube interconnects and nanosensor [1-8]. The application of single walled carbon nanotubes in electronic devices system requires the controlled placement of nanotubes. Hence, developing controlled-synthesis methods to obtain well-ordered carbon nanotubes is important and a viable route to nanotubes based devices. Dai et al. [9] showed self-directed growth of suspended nanotube networks on silicon tower tops having a liquid-phase catalyst precursor by chemical vapor deposition (CVD). Also recently Homma et al. [10] demonstrated the fabrication of suspended carbon nanotube networks on $100 \mathrm{~nm}$ scale silicon pillar structures by simply depositing a catalyst film on the silicon substrate. These are indeed effective ways to control the growth of carbon nanotubes. However, for the actual application of such self-assembled singlewalled carbon nanotube networks, additional efforts to build highly dense and organized nanotube networks connecting all designed locations even on a large scale are required.

In order to determine the growth sites of the SWNTs on the substrate, a resist pattern is defined lithographically, the liquid catalyst material is brought onto the surface, calcinated, 
and the excess catalyst then is removed in the lift-off step. In this paper, we present a systematic study to obtain high-yield growth of single-walled carbon nanotubes networks among catalyst islands. Based on our TEM results, a growth mechanism of CNTs on catalyst islands is described.

\section{EXPERIMENTAL}

A schematic of the process flow was shown in fig. 1 . The nanotubes were grown by a thermal CVD of methane at atmospheric pressure.

\subsection{Materials}

Silicon (100) wafer with surface oxide layer of thickness $300 \mathrm{~nm}$ was used as the substrate. All materials used in experiments are research grade materials purchased from different suppliers. $\mathrm{Fe}\left(\mathrm{NO}_{3}\right)_{3} \cdot 9 \mathrm{H}_{2} \mathrm{O}$, and $\mathrm{MoO}_{2}$ (acetylacetone $)_{2}$ were purchased from Sigma Aldrich chemicals. Oxide $\mathrm{C}$ alumina obtained from Degussa Inc. Air product provided highpurity methane and hydrogen.

\subsection{Catalyst preparation}

In the initial methane CVD method, we used an mixture of $40 \mathrm{mg} \mathrm{Fe}\left(\mathrm{NO}_{3}\right)_{3} .9 \mathrm{H}_{2} \mathrm{O}, 3 \mathrm{mg}$ $\mathrm{MoO}_{2}$ (acetylacetone) $)_{2}$, and $30 \mathrm{mg} \mathrm{Al}_{2} \mathrm{O}_{3}$ in methanol as a catalyst.

\subsection{Fabrication of pattern catalyst and growth of carbon nanotube}

In all experiments the thickness of the thermally grown oxide is typically $\sim 300 \mathrm{~nm}$, and isolates the devices from the back gate. A set of markers is necessary to later locate the position of the nanotubes and for the fabrication of the electrodes. These include a set of electron beam lithography alignment markers (e-beam markers) and atomic force microscopy (AFM) markers.

Substrates with markers are used as a substrate for this step.

Substrates with markers are used as a substrate for this step.

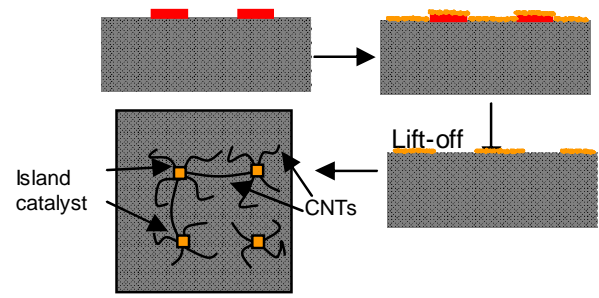

Figure 1. Patterned growth of CNTs

The liquid catalyst is deposited onto the substrate and blown dry. After lift-off in acetone, the substrate with patterned catalyst is placed in a 3-inch quartz tube furnace and the CVD is carried out at $900^{\circ} \mathrm{C}$ with $250 \mathrm{sccm} \mathrm{H}_{2}$, $1000 \mathrm{sccm} \mathrm{CH}_{4}$ for $10 \mathrm{~min}$. Argon is flown during heating up and cooling down. The methane and hydrogen flows have been optimized to obtain long and clean single walled carbon nanotubes with very slightly amorphous carbon deposition.

\subsection{Characterizations}

Markers samples were fully characterized using SEM. The properties of SWNTs in the methane CVD process was determined systematic by SEM, TEM, AFM and Raman spectroscopy. Using TEM grids as substrates 
for the growth of carbon nanotubes is a very simple approach. The TEM grids are thin metal foils with punched holes. The grids have a diameter of $3.05 \mathrm{~mm}$ and a thickness of 12 to $15 \mu \mathrm{m}$. The melting point of the grids' metals is higher than $1000^{\circ} \mathrm{C}$ which means that the grids should withstand the growth process.

\section{RESULTS AND DISCUSSION}

\subsection{Fabrication of pattern catalyst result}

We have characterized our samples with GEREMI scanning electron microscope (SEM).

In fig 2, we show two SEM micrographs recorded on markers and catalyst islands.

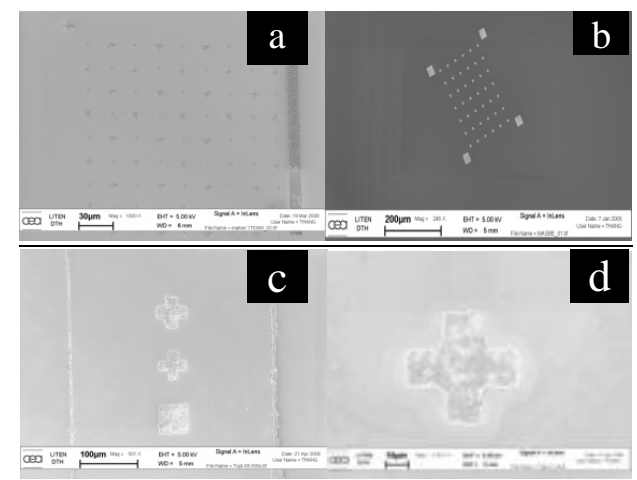

Figure 2. SEM images of markers (a) and patterned catalyst (b, c, d).

The dark areas (fig 2a) are the markers and the white areas (fig 2b, c, d) are the catalyst islands. These SEM results indicate: we have succeeded in the fabrication markers and obtained catalyst islands on silicon substrate.

\subsection{Patterned growth of SWNTs}

The quality and the uniformity of the carbon nanotubes on the catalyst islands were characterized by SEM and Raman.
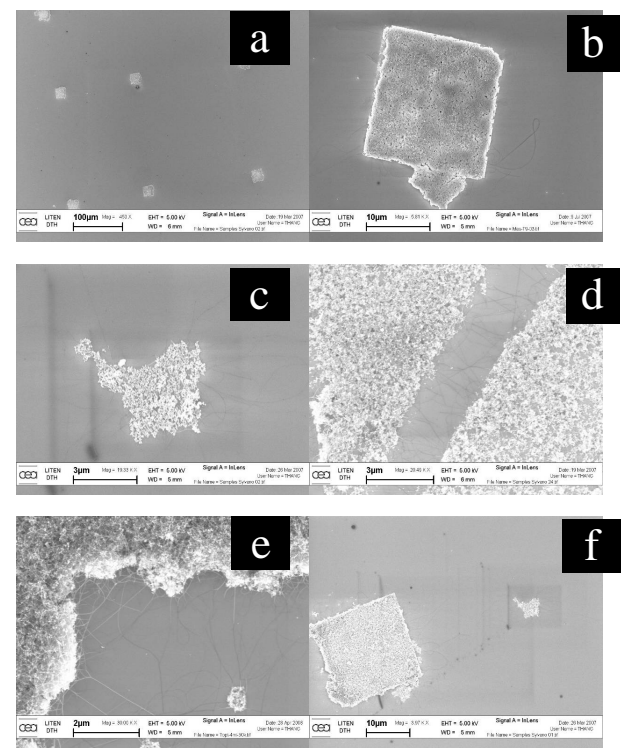

Figure 3. Scanning electron microscopy images of as-grown $\mathrm{CNTs}$ on/near catalyst islands

Fig 3 shows the growth behaviour of carbon nanotubes on patterned catalyst. Using a low magnification of SEM instrument allows direct observation of the catalyst islands and as-grown carbon nanotubes.

Fig. $3 b$ and $3 c$ present the nanotubes grown around the islands catalyst. Fig. 3d, e, f shows the obtained-nanotubes accross 3,4 and $20 \mu \mathrm{m}$ wide gaps, respectively.

In general, the growth of CNTs terminates upon touching another catalyst side (fig 3d-f). This allows us to control the length of CNTs by using the patterned catalyst with predefined gap. From our results patterned growth method has proved to be valid for pattern spacing up to $\sim 20 \mu \mathrm{m}$.

The SEM figures also reveal some features for catalyst pattern. The catalyst islands can be defined precisely to the micro-scale. In addition, catalyst pattern is not flat and uniform 
in general. In some region where the catalyst is suppose to be present, catalyst nanoparticles completely disappeared during lift-off.
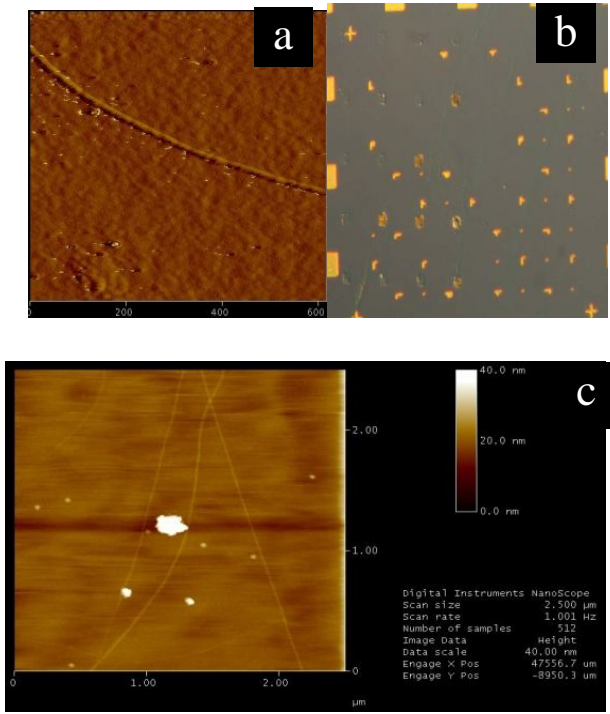

Figure 4. AFM images of as-grown CNTs from a patterned catalyst (with AFM markers)

An AFM working in tapping mode was used to image our samples. In this mode the tip extends into the repulsive regime (but not in direct contact) of the surface so the tip intermittently taps the surface.

Three representative AFM images are shown in Figure 4. The AFM results show an individual single wall carbon nanotube on the substrate's surface. Fig 4(b) illustrates the sample's surface after CVD process with the presence of the catalyst islands, AFM markers and the CNTs. The diameter of CNTs in Figure 4(c) is no greater than $1.8 \mathrm{~nm}$, which is typical of as-grown carbon nanotubes.

In addition, some SWNTs are observed near island (fig 4c). These long SWNTs are desired for device integrations.
The produced-CNTs on catalyst islands are also characterized by resonant Raman spectroscopy to determine the conducting properties and diameters. Raman spectrum in fig. 5 shows some specific features of the asgrown carbon nanotubes on the catalyst islands.

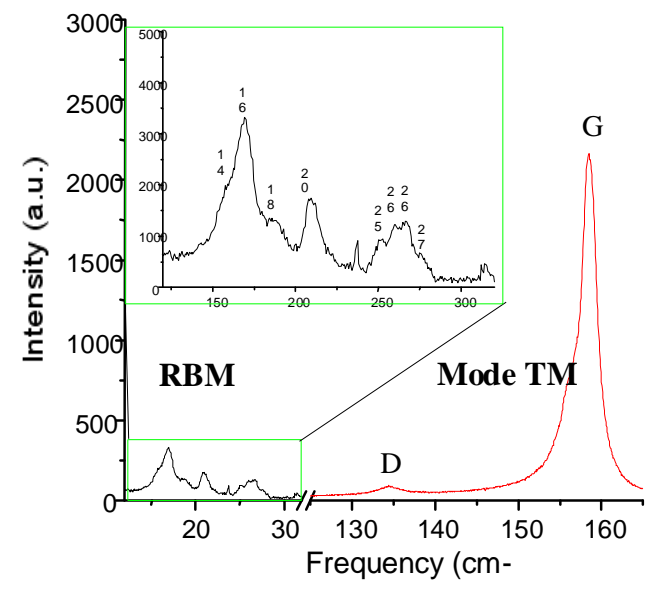

Figure 5. Raman spectroscopy of CNTs products

We were characterized SWNTs properties by a Raman microscope system (YVON) at an excitation wavelength of $514.5 \mathrm{~nm}$.

The diameter is determined by measuring the RBM frequency and applying the formula [3]:

$v_{\mathrm{RBM}}=224 / \mathrm{d}(\mathrm{nm})$

Raman spectra show several RBM signals, suggesting that the grown SWNTs are bundles or individuals nanotubes. The frequency range for the observed RBM signals $\left(120-300 \mathrm{~cm}^{-1}\right)$ corresponds to tube diameters from 0.8 to 2 nm. 
In the high-frequency range of the Raman spectra, we observe a prominent G-band ( $\left.1590 \mathrm{~cm}^{-1}\right)$ and the weak D-band $\left(\sim 1350 \mathrm{~cm}^{-1}\right)$. approximately proportional to density of SWNTs. The D-band is related to the structural disorder of $\mathrm{sp}^{2}$ bonded nanocrystalline and/or amorphous carbon species. Its low intensity is indicating that very few defects are presents in these SWNTs. The other feature of interesting is the very high ratio $I_{G} / I_{D}(\sim 24)$. This ratio confirms that high quality SWNTs are synthesized on the patterned catalyst.

The diameters and properties of producedSWNTs are calculated and shown in table 1.

\subsection{TEM images of carbon nanotube}

TEM pictures show the bundles and individual (fig. 6) single-walled carbon As it is well known, the G-band intensity is

nanotubes. These nanotubes have diameter of around $1.4 \mathrm{~nm}$. The observed bundle SWNT includes some parallel tubes with diameter in the range of 1.3-1.6 $\mathrm{nm}$.

Graphene layers covering the catalyst nanoparticles are seen together with catalyst particles in fig.6.

Table 1. Calculated diameter from RBM peaks of SWNTs on patterned catalyst

\begin{tabular}{|c|c|c|}
\hline$\omega_{\text {RBM }}$ & $\mathrm{d}(\mathrm{nm})$ & CNTs properties \\
\hline 130 & 1.72 & Semiconductor \\
\hline 140 & 1.6 & Semiconductor \\
\hline 152 & 1.47 & Semiconductor \\
\hline 170 & 1.32 & Semiconductor \\
\hline 200 & 1.12 & Metallic \\
\hline 270 & 0.83 & Metallic, Semiconductor \\
\hline 290 & 0.77 & Semiconductor \\
\hline
\end{tabular}

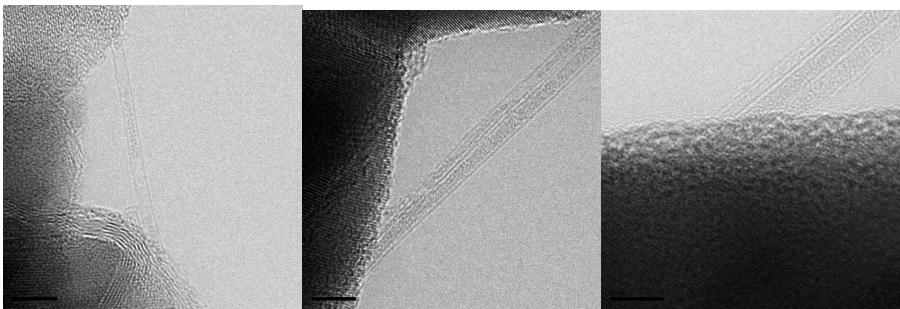

Figure 6. TEM images of individual SWNTs

TEM studies of carbon nanotubes demonstrated different single walled carbon nanotubes (the individual and bundles of SWNTs). In some of images, catalyst particles, on which the carbon nanotubes were grown, were also observed. In our case, most of the individual SWNTs have diameter smaller than $2 \mathrm{~nm}$. The TEM results also confirmed that the
MWNT and DWNT didn't grow on our process.

\subsection{The growth mechanism of CNT}

With TEM images, we found that the bottoms of nanotubes are attached by small catalyst particles. In all cases, the SWNT's bottoms with catalyst nanoparticles are found 
to be always anchored on the alumina support (red arrows in fig 7).

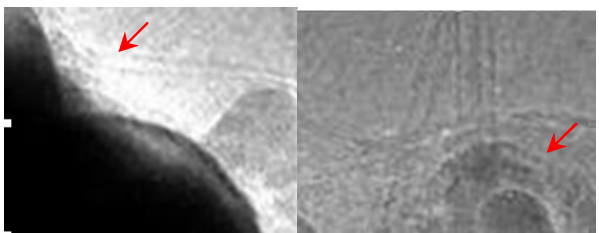

Figure 7. A typical HRTEM images of the SWNTs' bottoms

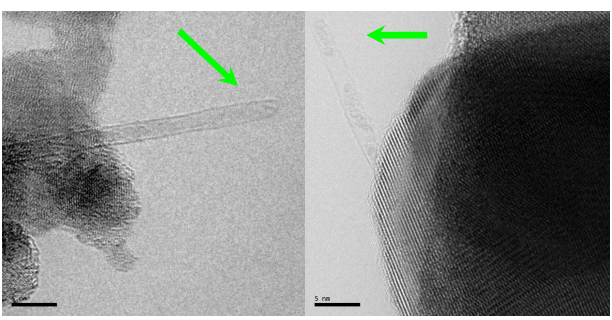

Figure 8. TEM images of SWNTs without catalytic particles at the SWNTs' top

Figure 8 shown the top of the tubes can extend out of the grid. Importantly, we have not seen a SWNT extending out of grid with the catalyst nanoparticles on the top (bright green arrows in figure 8).

Based on the states of the nanotubes ends and the TEM results, we propose that SWNTs grow via the "base-growth" model. In addition, to explain the growth mechanism of carbon nanotubes in methane CVD process, the vaporliquid-solid (VLS) model is proposed to explain the growth of carbon nanotubes [3].

\section{CONCLUSION}

Outcomes the patterned growth of SWNTs on silicon substrate has been proved successful. A majority of single wall carbon nanotubes emanation from the catalyst sites are obtained. The produced-SWNTs are a mixture of the semiconducting and metallic with the diameters in the range of $0.8-1.8 \mathrm{~nm}$. These CNTs emanation far away from the catalyst sites, which based on "base-growth" mechanism, are of special importance for the device applications.

Thanks to their very long length, we are able to deposit metal leads to these CNTs. The results here shall pave the way for patterned growth at the individual catalytic nanoparticle level, nanotube orientation control and device integration in a scalable fashion for future nanoelectronics. 


\title{
TỔNG HỢP ỐNG NANO CARBON ĐƠN THÀNH BẰNG PHƯƠNG PHÁP NGƯNG TỤ HƠI HÓA HỌC TÙ CƠ CHẾ HÌNH THÀNH ĐẾN PHÁT TRIỂN TẠI CÁC VÙNG ĐỊNH VỊ XÚC TÁC HỨ̛́NG ĐẾN ÚNG DỤNG TRONG LINH KIỆN ĐIỆN TỬ
}

\author{
Lê Văn Thăng \\ Trường Đại học Bách Khoa, ĐHQG-HCM
}

TÓM TÄT: Nghiên cứu kiểm soát và phát triển có chọn lọcống nano carbon đơn thành tại các vị trí xácđịnh nhằm huớng tới cácúng dụng trong lĩnh vục linh kiện điện tử đãđược thụcc hiện. Trong bài báo, ống nano carbon đon thành với đưòng kính trong khoảng 0.8-1.8 nm đãđược tổng hợp trên nền đế silicon. Phương pháp tổng hợp này cho phép thu được cácống nano carbon đơn thành tại các vị trí mong muốn và mở ra khả năng thực hiện việc phát triển kết hợp với tự kết nối giũa cácđiện cực bằng ống nano carbon đơn thành. Bên cạnh đó, cơ chế phát triển ống nano carbon đơn thành cũng được xác định rõ trong nghiên cúu. Hướng kết hợp quá trình tổng hợp và kỹ thuật vi chế tạo cho phép hình thành trục tiếp các cầu nối ống nano carbon với ưu thế là có thể kiểm soát chiều dài cũng nhu vị trí của các cầu nối trên nền vật liệu ống nano carbon đơn thành đã bước đầu thành công.

Tù khóa: Ông nano carbon đơn thành, linh kiện điện tử, kính hiển vi điện tủ̉ truyền qua, đảo xúc tác

\section{REFERENCES}

[1]. Pulickel M. Ajayan, Otto Z. Zhou, Applications of Carbon Nanotubes, Appl. Phys. 80, 391-425 (2001).

[2]. M. Meyyappan, Carbon nanotubes science and applications, CRC PRESS (2005).

[3]. A. Loiseau P. Launois P. Petit, S. Roche J.-P. Salvetat, Understanding Carbon Nanotubes. Springer (2006).

[4]. A. A. Puretzky, H. Schittenhelm, X. Fan, M. J. Lance, L. F. Allard, Jr., and D. B. Geohegan,Investigations of single-wall carbon nanotube growth by time-restricted laser vaporization, Phys. Rev. B 65, 245425 (2002).
[5]. J. Kong, A. Cassell and H. Dai. Chemical Vapor Deposition of Methane for SingleWalled Carbon Nanotubes, Chem. Phys. Lett., 292, 567 (1998).

[6]. Jing Kong, H. T. Soh, A. Cassell, C. F. Quate, H. Dai, Synthesis of Individual Single-Walled Carbon Nanotubes on Patterned Silicon Wafers, Nature, 395, 878 (1998).

[7]. Y. Gogotsi, Carbon nanomaterials, Taylor and Francis Group, LLC (2006)

[8]. Gary G. Tibbetts, Why are carbon filaments tubular? Jour. Crys. Growth. 66,632-638 (1984).

[9]. H. Dai, J. Kong, Ch. Zhou, N. Franklin, T. Tombler, A. Cassell, S. Fan and M. 


\section{TAP̈ CHÍ PHAÙ TRIEÂ KH\&CN, TAR̈ 16, SOÁK1- 2013}

Chapline. Controlled chemical routes to

nanotube Architectures, Physics, and

Devices. J, Phys. Chem. B 103, 11246-

11255 (1999).
[10]. Y. Homma, Y. Kobayashi, T. Ogino, and T. Yamashita,Growth of suspended carbon nanotubes networks on 100-nm-scale silicon pillars, Appl. Phys. Lett. 81, 22612263 (2002). 